\title{
Ozonated autohemotherapy: protection of kidneys from ischemia in rats subjected to unilateral nephrectomy
}

\author{
Chiara Foglieni ${ }^{1}$, Alessandro Fulgenzi ${ }^{2}$, Daniela Belloni ${ }^{3}$, Clara Sciorati ${ }^{4}$, Elisabetta Ferrero ${ }^{3}$ and \\ Maria Elena Ferrero ${ }^{2 *}$
}

\begin{abstract}
Background: Ozonated autohemotherapy $(\mathrm{OA})$ has been previously successfully used in the treatment of patients affected by peripheral occlusive arterial disease. OA consists of an intrafemoral reinfusion of autologous blood previously exposed to a mixture of oxygen/ozone $\left(\mathrm{O}_{2} / \mathrm{O}_{3}\right)$. This study analyzes the effects of OA in protecting rat kidney from ischemia and ischemia/reperfusion damage.

Methods: We performed OA 30 min before the induction of 60 min renal ischemia or at the induction of 60 min postischemic reperfusion in rats subjected to unilateral nephrectomy. In addition, to evidence the possible protection induced by $\mathrm{O}_{2} / \mathrm{O}_{3}$ on endothelial functions, the present study analyzes the in vitro effects of $\mathrm{O}_{2} / \mathrm{O}_{3}$ on oxygen consumption by human umbilical vein endothelial cells (HUVEC).

Results: 1) OA preserves rat kidney functions and architecture, as demonstrated by the improved levels of serum creatinine and blood urea nitrogen and by histology; 2) such protection does not correlate with the increase of plasmatic nitric oxide, but is compatible with a focal renal increase of renal $\beta \mathrm{NADPH}$-diaphorase; 3 ) treatment of HUVEC with $\mathrm{O}_{2} / \mathrm{O}_{3}$ significantly increases both the rate of oxygen consumption and the mitochondrial activity assessed by confocal microscopy.
\end{abstract}

Conclusion: The preservation of the mitochondrial activity of endothelium could in vivo limit the endothelial dysfunction provoked by the Isc or Isc/R processes.

\section{Background}

The controversial debate on the beneficial versus the toxicological actions of ozone $\left(\mathrm{O}_{3}\right)$, is still open [1]. However, if $\mathrm{O}_{3}$ is judiciously used within the precisely determined therapeutic window, it does not cause toxic effects [2-4]. Few relevant clinical applications demonstrate that Oxygen-Ozone $\left(\mathrm{O}_{2} / \mathrm{O}_{3}\right)$ autohemotherapy (OA, i.e. slow re-infusion of autologous blood previously exposed to a $\mathrm{O}_{2} / \mathrm{O}_{3}$ mixture), is useful in cardiovascular disorders and tissue ischemia, as well as supportive in viral infections through stimulation of the immune system $[1,2]$. In patients with peripheral occlusive arterial disease, OA improves hemorheological parameters and

\footnotetext{
* Correspondence: mariaelena.ferrero@unimi.it

${ }^{2}$ Dipartimento di Morfologia Umana e Scienze Biomediche - Città Studi,

Università degli Studi di Milano, Milan, Italy

Full list of author information is available at the end of the article
}

$\mathrm{O}_{2}$ delivery to tissues. [3]. Moreover, OA improves the capability of erythrocytes to deliver $\mathrm{O}_{2}$ to ischemic tissues, and finally induces a localized release of protective nitric oxide (NO), $\mathrm{CO}$ and growth factors from platelets $[1,2]$.

Ischemia (Isc) and Ischemia/Reperfusion (Isc/R)related injuries are major causes of acute kidney injury following renal transplantation. Despite tolerance induction, long-term surviving kidney allografts can develop chronic damages [4,5]. Among the $\mathrm{O}_{2}$-based methods, $\mathrm{O}_{2} / \mathrm{O}_{3}$ preconditioning, i.e. intra-peritoneum injection of $\mathrm{O}_{2} / \mathrm{O}_{3}$ mixture before ischemic damage, is an efficient protective system from rat Isc/R in both liver [6] and kidney $[7,8]$. In the renal model, $\mathrm{O}_{2} / \mathrm{O}_{3}$ preconditioning increases the expression of endothelial and inducible forms of NO synthase (eNOS, iNOS, respectively), and the NO release [9], with a mechanism similar to that 
induced by Isc preconditioning. The latter is an experimental model of brief, sequential ischemic events, that results in protecting against subsequent ischemic episodes. In comparison with both Isc and $\mathrm{O}_{2} / \mathrm{O}_{3}$ preconditioning, OA could have the considerable advantage of being feasible in humans. In our knowledge, no clinical or experimental data are presently available on OA role in protecting from renal Isc/R injury. Aim of the present study was to investigate if OA could be proposed to improve renal damage following Isc and Isc/R, in comparison with $\mathrm{O}_{2}$ alone.

Endothelial cells have been proposed to be elective targets of the positive molecular effects of ozone and its derived species formed during blood ozonation [10]. As mechanism of action, we have hypothesized that $\mathrm{O}_{2} / \mathrm{O}_{3}$ could locally increase the $\mathrm{O}_{2}$ availability for endothelial cells, supporting their resistance to dysfunction, thus contributing to protection of organs from Isc/R damage. Indeed, we evaluated: the effects of OA on renal morphology and function in rats subjected to Isc or Isc/R; plasmatic nitric oxide (NO) levels and renal iNOS isoform expression, because of the cytoprotective role of $\mathrm{NO}$ in Isc/R $[11,12]$. The effects of $\mathrm{O}_{2} / \mathrm{O}_{3}$ on endothelium were also investigated on rat renal arteries through expression of CD31/PECAM1, and in vitro through measurements of $\mathrm{O}_{2}$ consumption, mitochondrial oxidative activity and cell metabolism.

\section{Methods}

\section{Animals}

Male adult Wistar rats (Harlan Italy, S.Pietro al Natisone, Udine, Italy), 230-250 g, were used. The rats had free access to standard pelleted food and water and were maintained at temperature of $22 \pm 1^{\circ} \mathrm{C}$ with a $12 \mathrm{~h}$ light/dark cycle. All experimental procedures conformed to the "guide for the care and the use of Laboratory Animals published by the US National Institute of Health (NIH publication NO: 85-23, revised 1996), according to the animal welfare regulations of the Italian local authorities (Ethical Committee of the University of the Studies of Milan, Italy).

\section{Experimental groups}

We submitted rats to Isc followed by brief $\mathrm{R}$ time, because kidney damages occur early during $\mathrm{R}$ and previous authors already studied the effects of ozone-oxidative preconditioning after long $\mathrm{R}$ time [7-9]. Moreover, we submitted rats to unilateral nephrectomy to avoid the controlateral kidney influence before to induce Isc.

The rats were randomly assigned to 8 groups $(n=7$ rats/group). All the rats were treated with autologous blood groups 1 to 8 by intrafemoral injection. Groups 1 and 5 were unoperated (e.g. controls); groups 2 and 6 sham operated (e.g. rats undergoing the surgical procedure without clamp of the left renal artery); groups 3 and 7 were ischemized (Isc); groups 4 and 8 were ischemized and reperfused (Isc/R). In groups 2 to 4 and 6 to 8 the rats underwent right kidney nephrectomy before any other treatment. In groups 1, 2, 3, 4. autologous blood was treated with $\mathrm{O}_{2}$ alone. In groups 5, 6, 7, 8 autologous blood was treated with $\mathrm{O}_{2} / \mathrm{O}_{3}$ mixture (OA) Intrafemoral injection of autologous blood or OA was performed $30 \mathrm{~min}$ before the rat killing in groups 1 and 5 , or 30 min after right kidney removal in groups 2 and 6 , respectively. Groups 3 and 7 received a single intrafemoral injection of the blood $30 \mathrm{~min}$ before Isc (indeed underwent Isc). Groups 4 and 8 received a single intrafemoral injection of the blood at the time of clamp removal (e.g. at R). Sampling was performed after 60 min reperfusion. The characteristics of the different groups are reported in Table 1.

\section{Isc/R model}

Rats were anesthetized inhaling a mixture of halothane $2 \%$ (Hoechst, Milano, Italy) in oxygen. They were placed on a temperature-regulated table $\left(38^{\circ} \mathrm{C}\right.$ ) (Ugo Basile, Comerio, Lecco, Italy) to maintain body temperature. Isc was induced in kidneys by clamping the left renal artery and the left renal vein for 60 min with a microsurgical clamp. $\mathrm{R}$ was obtained by removing vascular clamp and lasted $60 \mathrm{~min}$. During the surgical procedure heart rate and mean arterial blood pressure were monitored. At the end of Isc or of Isc/R, rats were exanguinated at the aorta bifurcation level, blood samples were recovered, and kidneys were collected from 4 animals/ group and processed for histological analysis. During the surgical procedure the heart rate and the mean arterial blood pressure were monitored, as previously described [13].

\section{Ozonated autohemotherapy}

First of all we set up the optimal $\mathrm{O}_{2} / \mathrm{O}_{3}$ concentration. An ozone generator (Multiossigen, Gorle, Bergamo, Italy) was used to erogate the $\mathrm{O}_{2} / \mathrm{O}_{3}$ gas mixture, composed of an equivalent volume of ozone-oxygen (1:1

Table 1 Experimental groups of rats

\begin{tabular}{lccc}
\hline GROUPS & & $\mathbf{O}_{\mathbf{2}} / \mathbf{O}_{\mathbf{3}}$ & AUTOHEMOTHERAPY \\
\hline GROUP 1 & CONTROLS & - & 30 ' before killing \\
\hline GROUP 2 & "SHAM OPERATED" & - & $30^{\prime}$ after right kidney removal \\
\hline GROUP 3 & ISC & - & 30 ' before IsC \\
\hline GROUP 4 & ISC/R & - & at $R$ \\
\hline GROUP 5 & CONTROLS & + & 30 ' before killing \\
\hline GROUP 6 & "SHAM OPERATED" & + & 30 ' after right kidney removal \\
\hline GROUP 7 & ISC & + & 30 before Isc \\
\hline GROUP 8 & ISC/R & + & at R \\
\hline
\end{tabular}


volume relationship). Ozone concentration in the mixture was $50 \mu \mathrm{g} / \mathrm{ml}$, per $\mathrm{ml}$ of blood, known to not cause oxidative injury in vivo [14]. Rat blood $(1 \mathrm{ml})$ was drawn from the caudal vein into a sterile glass tube; and $20 \mu \mathrm{l}$ heparin (5000 U.I./ml, Vister, Parke-Davis, Lainate, Milano, Italy) was used as an anticoagulant. Tube was connected to the ozone generator and $1 \mathrm{ml}$ blood ex vivo exposed to $5 \mathrm{ml}$ of gas mixture. During the exposure to the gas mixture (4 min) blood was continuously and gently shaken until it appeared light red, then was re-infused into the left femoral vein of the donor rat. No other medication was given. Autohemotherapy with the administration of medical oxygen was performed as a control treatment.

\section{Functional studies}

Serum creatinine was measured using a modified Jaffe's reaction and blood urea nitrogen was measured on the AEROSET system (Abbott Laboratories, Abbott Park, IL) [13].

\section{Histopathology of rat kidneys}

Collected kidneys were fixed and processed as previously described [15]. Renal damage was evaluated on 4 to 6 sections stained with Hematoxylin/Eosin as tubular epithelial cell necrosis, tubular dilation, protein casts and medullary congestion. The alterations were semiquantitatively graded $(-=$ absent,$+=$ barely present, ++ $=$ moderate, $+++=$ severe) [16] instead of being submitted to statistical analysis, which was scarcely reliable in our conditions. Additional 4 to 6 sections from $\mathrm{O}_{2} /$ $\mathrm{O}_{3}$-treated rats were submitted to $\beta \mathrm{NADPH}$ diaphorase for evaluating NOS activity. In fact $\beta$ NADPH diaphorase histochemistry reflects the expression of total NOS in the rat kidney tissue [17]. Slides were incubated with 1 $\mathrm{mM} \beta \mathrm{NADPH} / 0.2 \mathrm{mM}$ nitroblue tetrazolium/100 mM Tris-HC1 buffer $\mathrm{pH} 8.0$ containing $0.2 \%$ Triton X-100 for $60 \mathrm{~min}$ at $37^{\circ} \mathrm{C}$ as described [13]. A pathologist who worked blindly analyzed the sections using Eclipse $55 \mathrm{i}$ microscope equipped with a DS-L1 camera (Nikon, Tokyo, Japan).

\section{Nitrite/Nitrate determination}

At the end of Isc and of Isc/R, $1 \mathrm{ml}$ of heparinized (not coagulated) blood was drawn at the aorta bifurcation of each rat to measure the NO concentrations. Blood samples underwent centrifugation and plasma aliquots were stored at $-21^{\circ} \mathrm{C}$ until determination. Plasma nitrite/ nitrate were determined using the Greiss reaction that measures combined oxidation products of $\mathrm{NO}$, plasma nitrite $\left(\mathrm{NO}_{2}{ }^{-}\right)$and nitrate $\left(\mathrm{NO}_{3}{ }^{-}\right)$after reduction with nitrate reductase in a colorimetric assay [18]. Standard curves with increasing concentrations of sodium nitrate and sodium nitrite were run in parallel.

\section{Isolation and culture of HUVEC}

Human umbilical vein endothelial cells (HUVEC) were isolated from human cord by collagenase treatment as described [19] and cultured in 1\% gelatin-coated flasks (Falcon; Becton Dickinson, Bedford, MA, USA) using endotoxin-free Medium 199 (BioWhittaker, Cambrex Bio Science Verviers, Belgium), containing 20\% heatinactivated fetal bovine serum (FBS, Hyclone, Logan, UT, USA), $1 \%$ bovine retinal-derived growth factor, 90 $\mu \mathrm{g} / \mathrm{ml}$ heparin, $100 \mathrm{I} . \mathrm{U} . / \mathrm{ml}$ penicillin, and $100 \mu \mathrm{g} / \mathrm{ml}$ streptomycin (Biochrom, Berlin, Germany). All experiments were carried out with HUVEC at passage 1-4.

\section{$\mathrm{O}_{2}$ consumption by HUVEC}

Consumption of $\mathrm{O}_{2}$ was measured using the Biological Oxygen Monitor System 5300A (YSI Incorporated, Yellow Springs, Ohio, USA) and Clark-type-polarographic $\mathrm{O}_{2}$ electrode. The data were recovered with WinWedge software (TAL Technologies, Philadelphia, PA, USA).

During $\mathrm{O}_{2}$ consumption measurements, the cells were placed in thermostatically-regulated chambers $\left(37^{\circ} \mathrm{C}\right)$ equipped with a magnetically stirred circulator. The instrument calibration was performed considering the levels of $\mathrm{O}_{2}$ as $24 \%\left(=\mu \mathrm{l}\right.$ of $\mathrm{O}_{2} / \mathrm{ml}$, corresponding to the volume of $\mathrm{O}_{2}$ dissolved in aqueous medium at $1 \mathrm{~atm}$ and $37^{\circ} \mathrm{C}$ ) [20]. $\mathrm{O}_{2}$ consumption values were recorded every $5 \mathrm{sec}$ for 15 to $60 \mathrm{~min}$. After $5 \mathrm{~min}$ of acclimatization, $\mathrm{O}_{2} / \mathrm{O}_{3}$ mixture was added in about 10 seconds $(2$ $\mathrm{ml}$, at the ozone concentration of $50 \mu \mathrm{g} \mathrm{O}_{3} / \mathrm{ml}$ ) through a PE 50 polyethylene tube [21].

\section{Measure of ATP and LDH levels in HUVEC}

Measure of oxygen consumption in HUVEC has been associated to the dosage of adenosine $5^{\prime}$ triphosphate (ATP) and lactate dehydrogenase (LDH). Briefly, HUVEC seeded on 6 well and 24 well plates respectively, were exposed to the $\mathrm{O}_{2} / \mathrm{O}_{3}$ mixture $(2 \mathrm{ml}$ at the concentration of $1 \mu \mathrm{l} / \mathrm{ml}$ ) for about 2 minutes; after that, ATP and LHD contents were measured at different time intervals (e.g. 5, 30, 60, 90, $120 \mathrm{~min}$ ). The assays were performed in quadruplicate. ATP luminescence assay kit (Invitrogen, San Giuliano Milanese, Milano, Italy) and LDH assay kit (Cytotoxicity Colorimetric assay kit, Oxford Biochemical Research INC, Oxford, MI, USA) have been used. ATP levels have been referred to HUVEC protein content, whereas LDH to the volume $(\mathrm{ml})$ of cell suspension.

\section{HUVEC protein content assay}

Cell protein content has been measured by the colorimetric method, using Coomassie brilliant blue G-250 (BioRad Laboratories, Richmond, CA, USA). Cells were previously lysated as described in the manifacture 
protocol. Bovine serum albumin was used as standard (BioRad protein assay).

\section{Confocal microscopy on HUVEC}

Mitochondria and nuclear activities were labeled on living HUVEC, grown on glass coverslips $\left(10^{5}\right.$ cells/coverslip) with mitoTraker CMX-ROS (250 nM, $40 \mathrm{~min}, 37^{\circ}$ C) (Molecular Probes, Eugene, OR) and with acridine orange (Sigma-Aldrich, St. Louis, Missouri) [17], prior to insufflate cells with $1 \mathrm{ml} \mathrm{O} / 2 / \mathrm{O}_{3}$. mixture.

Time-course confocal microscopy was performed using a Leica TCS SP2 AOBS (Leica Microsystems $\mathrm{GmbH}$, Wetzlar Germany) confocal microscope. Free projection max (FPM) images were obtained from single channels-collected Z-series, acquired before the $\mathrm{O}_{2} / \mathrm{O}_{3}$ treatment, at the moment of $\mathrm{O}_{2} / \mathrm{O}_{3}$ addition ( $\mathrm{t} 0$ ), after $5,10,20,30,60,120,180 \mathrm{~min}$ (t 1-t 7) from $\mathrm{O}_{2} / \mathrm{O}_{3}$ addition. Single-channel FPM were merged with Adobe Photoshop CS.

\section{Statistical Analysis}

Results were expressed as the mean \pm SEM. We performed Student's t test to analyse the distribution of the groups. Indeed, we performed Kolmogorov-Smirnov test and ANOVA test to analyse the differences between groups; $p$ values less than 0.05 were considered significant.

\section{Results}

In the rats studied the heart rate did not significantly vary during the experimental procedure, whereas mean arterial pressure significantly increased during ischemia (data not shown) [13]. Post-surgery polyuria or oliguria were not evidenced.

\section{OA improves renal dysfunction induced by both Isc and Isc/R}

We compared renal functions of rats subjected to $\mathrm{O}_{2}$ and $\mathrm{O}_{2} / \mathrm{O}_{3}$ autohemotherapy (A vs. B, Table 1). Both Isc and Isc/ $\mathrm{R}$ significantly increased serum creatinine and blood urea nitrogen levels in respect to controls and sham-operated animals. Notably, pre-treatment with OA (group B) protected kidneys from damage due to Isc or Isc/R, keeping serum creatinine and blood urea nitrogen at values comparable to those measured in controls and in shamoperated rats, but significantly lower than Isc- and Isc/Rinduced animals, not submitted to OA (Figure 1).

\section{OA protects kidneys from histological damages inflicted by Isc and Isc/R}

Tubular alteration is commonly considered an indicator of Isc renal damage, and alterations in intrarenal microcirculation and $\mathrm{O}_{2}$ handling can contribute to organ dysfunction, leading to Isc-related acute kidney injury $[7,11]$. Early alteration of peritubular capillary blood flow during reperfusion has been previously related to loss of normal endothelial cell function and Isc preconditioning prevents endothelial dysfunction [22,23].

Histological findings were summarized in Table 2 and Figure 2. Kidneys from Isc- and Isc/R-submitted rats displayed tubular necrosis, medullary congestion and glomerular damages in comparison to kidneys from control and sham-operated rats, accordingly with our previous findings [13]. In particular, focal glomerular damage, i.e. persistence of protein casts engulfing glomerular capillaries and Bowman spaces, was observed in Isc/R animals. OA treatment was able to reduce this tubulo-medullary damages, in particular preserved glomerular morphology.

\section{OA effects on: nitrite/nitrate, $\beta$ NADPH-diaphorase, iNOS, CD31/PECAM1}

As expected, both Isc and Isc/R significantly decreased plasmatic nitrite/nitrate levels. OA did not significantly affect these levels (Figure 3A). Endothelial damage was investigated locally, through the expression of the endothelial marker CD31/PECAM1 in renal tissue. Its bright expression was evident on endothelial cells of cortical arterioles (Figure 3B) from OA-treated Isc/R rats at a level comparable to control animals, and to a lesser extent in OAtreated Isc rats. In animals not submitted to OA, a faint signal was detected in Isc/R and no label in Isc. Overall, these results indicate an endothelial alteration when rats undergoing Isc or Isc/r did not receive OA. Consistently, the inducible isoform of NOS, iNOS (Figure 3C), appeared focally and weakly expressed on glomerular capillaries of Isc, but not Isc/R rats in the absence of OA. In OA-treated rats iNOS was weak in Isc/R, but intense in Isc on glomerular capillaries, suggesting an activation of iNOS by OA treatment. Some CD31/PECAM1 was focally observed into glomerular capillaries, mostly in controls animals.

The isoform non-specific NOS activity, evaluated by $\beta N A D P H$-diaphorase histochemistry, which indicated $\beta N A D P H$ oxidation in the renal tissue (Figure 3D), showed a decrease of both glomerular and tubular signal in damaged areas of the cortex, and of tubular activity in the medulla of Isc animals as compared to controls. This focal loss was more evident in the absence than in the presence of OA. Of note, areas of $\beta \mathrm{NADPH}$-diaphorase intense signal were observed in the less injured cortical regions of Isc rats renal cortex. In kidney of rats submitted to OA an increase with respect to controls of tubular signal was observed in the cortex and in the medulla.

\section{$\mathrm{O}_{2} / \mathrm{O}_{3}$ mixture improves $\mathrm{O}_{2}$ consumption of HUVEC via increase of mitochondrial activity}

HUVEC in basal conditions displayed poor $\mathrm{O}_{2}$ consumption. Administration of $\mathrm{O}_{2} / \mathrm{O}_{3}$ mixture early increased $\mathrm{O}_{2}$ disposal, that was rapidly consumed 


\section{Serum creatinine}

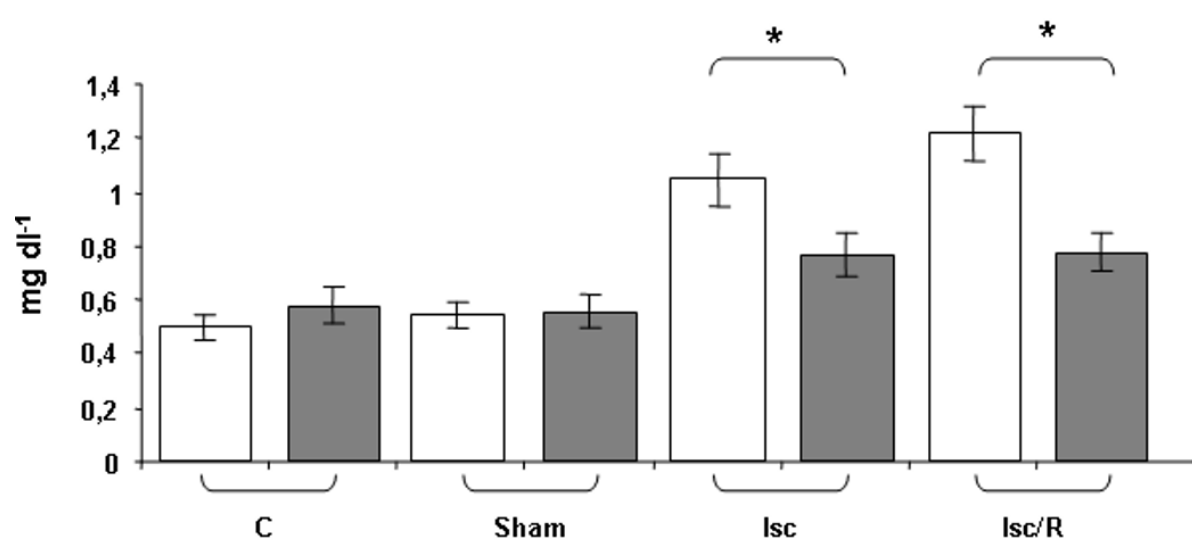

$\square+02$

$\square+02 / 03$

\section{Blood Urea Nitrogen}

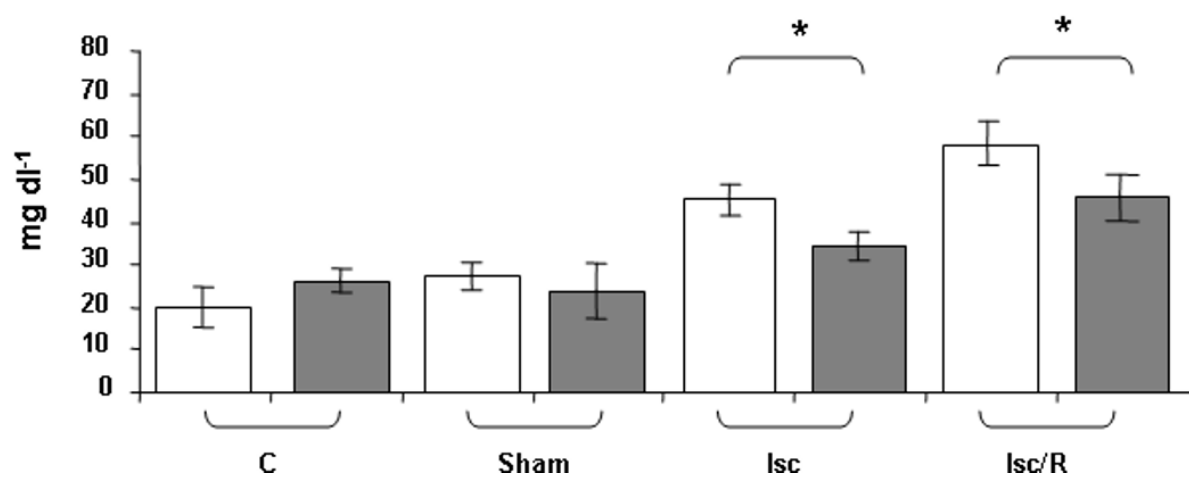

Figure 1 Effect of ozonated autohemotherapy on renal function after Isc and Isc/R. The rats received an intrafemoral injection of their blood driven from caudal vein and treated with $\mathrm{O}_{2}$ or a mixture of $\mathrm{O}_{2} / \mathrm{O}_{3}$; the injection was performed 30 min before Isc or at the induction of post-Isc R. Serum creatinine and blood urea nitrogen levels were measured. Isc and Isc/R rats subjected to $\mathrm{O}_{2} / \mathrm{O}_{3}$ autohemotherapy showed significant reductions of serum creatinine and blood urea nitrogen levels as compared with animals subjected to $\mathrm{O}_{2}$ autohemotherapy. Abbreviations: $\mathrm{C}=$ controls rats, Sham $=$ sham-operated rats, IsC = rats submitted to $60 \mathrm{~min}$ of ischemia by clamping the renal artery; Isc/R= rats submitted to $60 \mathrm{~min}$ of ischemia followed by 60 min reperfusion. ${ }^{*} p<0.05$

Table 2 Histopathology of rat kidneys

\begin{tabular}{|c|c|c|c|c|c|c|c|}
\hline & Group & Tubular necrosis & Tubular dilation & Protein casts & Medullary congestion & Glomerular damage & Interstitial stasis \\
\hline & 1 control & - & - & - & - & - & - \\
\hline \multirow[t]{4}{*}{ A } & 2 sham-operated & - & - & - & - & - & $+/-$ \\
\hline & 3 IsC & - & + & + & $+/++$ & - & ++ \\
\hline & $4 \mathrm{Isc} / \mathrm{R}$ & + & ++ & +++ & + & - & + \\
\hline & 5 control & - & - & - & - & - & - \\
\hline \multirow[t]{3}{*}{ B } & 6 sham-operated & - & - & - & - & - & $+/-$ \\
\hline & $7 \mathrm{IsC}$ & + & - & $+/-$ & + & + & ++ \\
\hline & $8 \mathrm{Isc} / \mathrm{R}$ & + & + & ++ & $+/+/-$ & + & + \\
\hline
\end{tabular}

(A) Autologous blood $+\mathrm{O}_{2}$

(B) Autologous blood $+\mathrm{O}_{2} / \mathrm{O}_{3}$ 


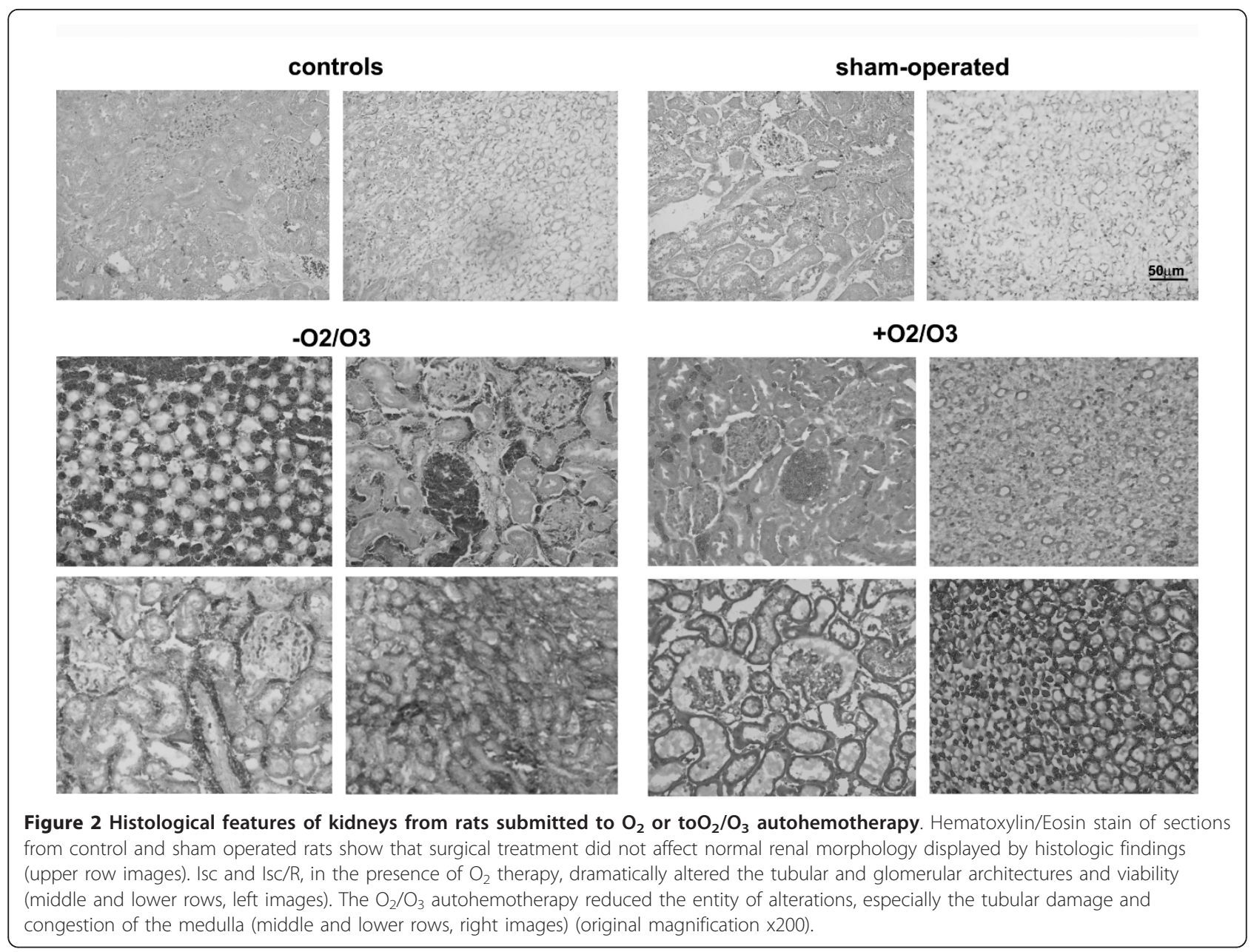

(Figure 4A). The total amount of $\mathrm{O}_{2}$ consumed by $\mathrm{O}_{2} /$ $\mathrm{O}_{3}$-treated HUVEC in $10 \mathrm{~min}$, increased six-fold in comparison with untreated cells (Figure 4B). Confocal microscopy of HUVEC, 2 min after addition of the $\mathrm{O}_{2} /$ $\mathrm{O}_{3}$ mixture (t0), showed a marked increase of both mitochondrial activity and Acridine orange signal as compared to basal fluorescence (Figure 4C panels a, b). Changes are compatible with the increased intracellular bioavailability of $\mathrm{O}_{2}$ suggested by the rapid rise in $\mathrm{O}_{2}$ consumption (Figure 4A). The effect reverted slowly to basal after $30 \mathrm{~min}$ from $\mathrm{O}_{2} / \mathrm{O}_{3}$ exposure (Figure $4 \mathrm{C}$ panel c). Confocal analysis performed $3 \mathrm{~h}$ after $\mathrm{O}_{2} / \mathrm{O}_{3}$ exposure, demonstrated that HUVEC mitochondrial activity and Acridine orange signal were comparable to basal (data not shown), thus indicating the absence of metabolic degeneration following the treatment.

\section{OA increases ATP production, without affecting LDH, in HUVEC}

After brief $\mathrm{O}_{2} / \mathrm{O}_{3}$ exposure, HUVEC were maintained in culture for up to $2 \mathrm{~h}$. Total cellular ATP content, expressed in $\mathrm{pmol} / \mathrm{mg}$ cellular protein, significantly increased at 30 and $60 \mathrm{~min}$ (Figure 5, upper panel) whereas LDH levels, expressed in U/ml, did not significantly vary (Figure 5, lower panel). ATP significantly increased 30 min after $\mathrm{O}_{2} / \mathrm{O}_{3}$ exposure, in agreement with the increase in mitochondrial activity (Figure 4C), suggesting that $\mathrm{OA}$ improves mitochondrial function.

\section{Discussion}

The main objective of this study is to investigate if the OA, which is used in patients affected by PAOD, could be proposed as a possible method to reduce damage due to Isc and/or postischemic R. We tested our hypothesis in vivo using an experimental model of Isc and Isc/R in rat kidney and in vitro using the possible target of Isc damage, e.g. HUVEC. In the present work blood samples were exposed to a mixture of $\mathrm{O}_{2} / \mathrm{O}_{3}$, , and then reinfused in the donor rat, and compared to that exposed to $\mathrm{O}_{2}$ alone before re-infusion. The advantages of our proposed therapy over preconditioning is to reduce the number of treatments in the time and to permit a more direct availability of ozone to the Isc organ due to intravenous treatment. We raised the question whether the 


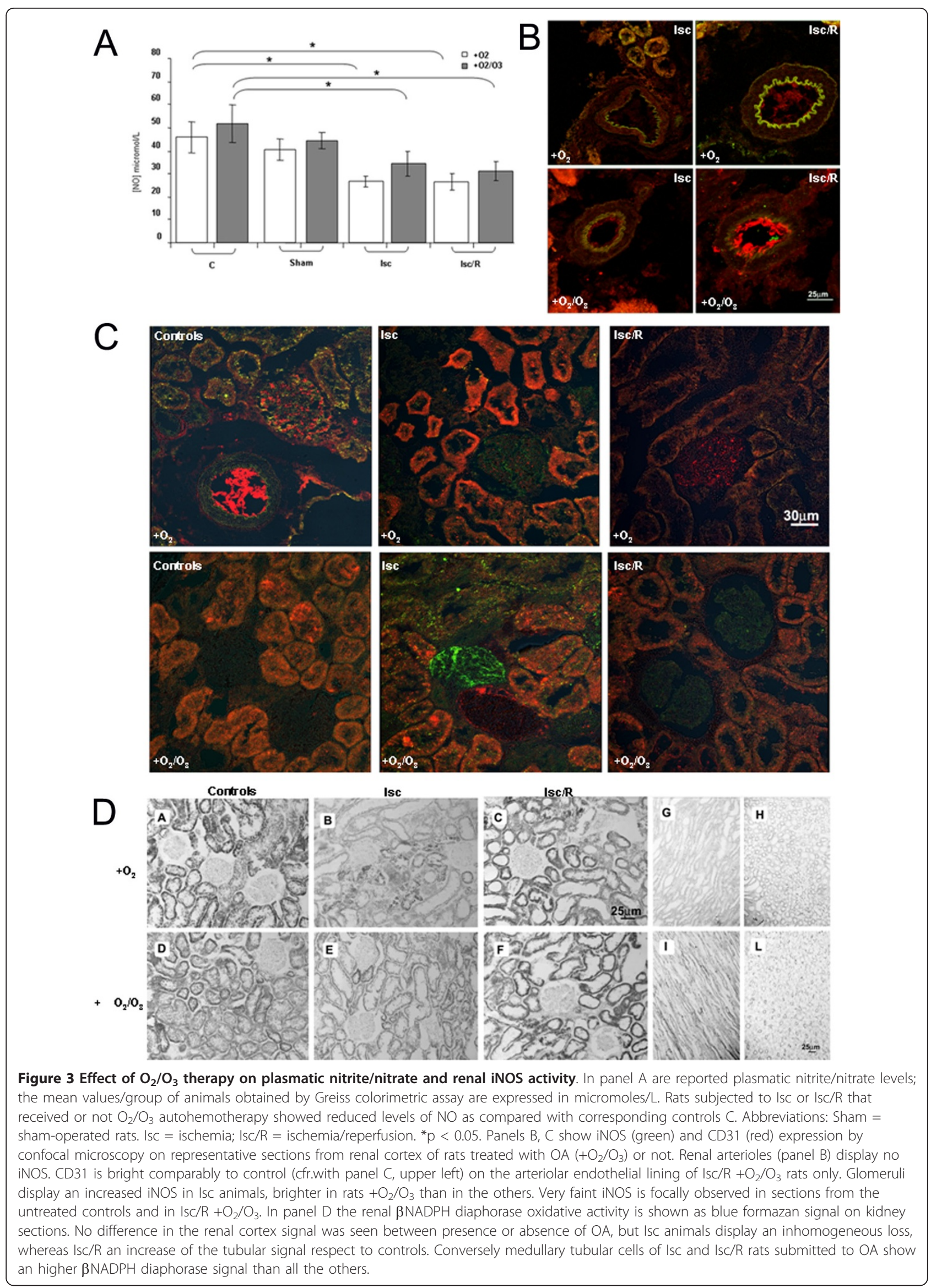




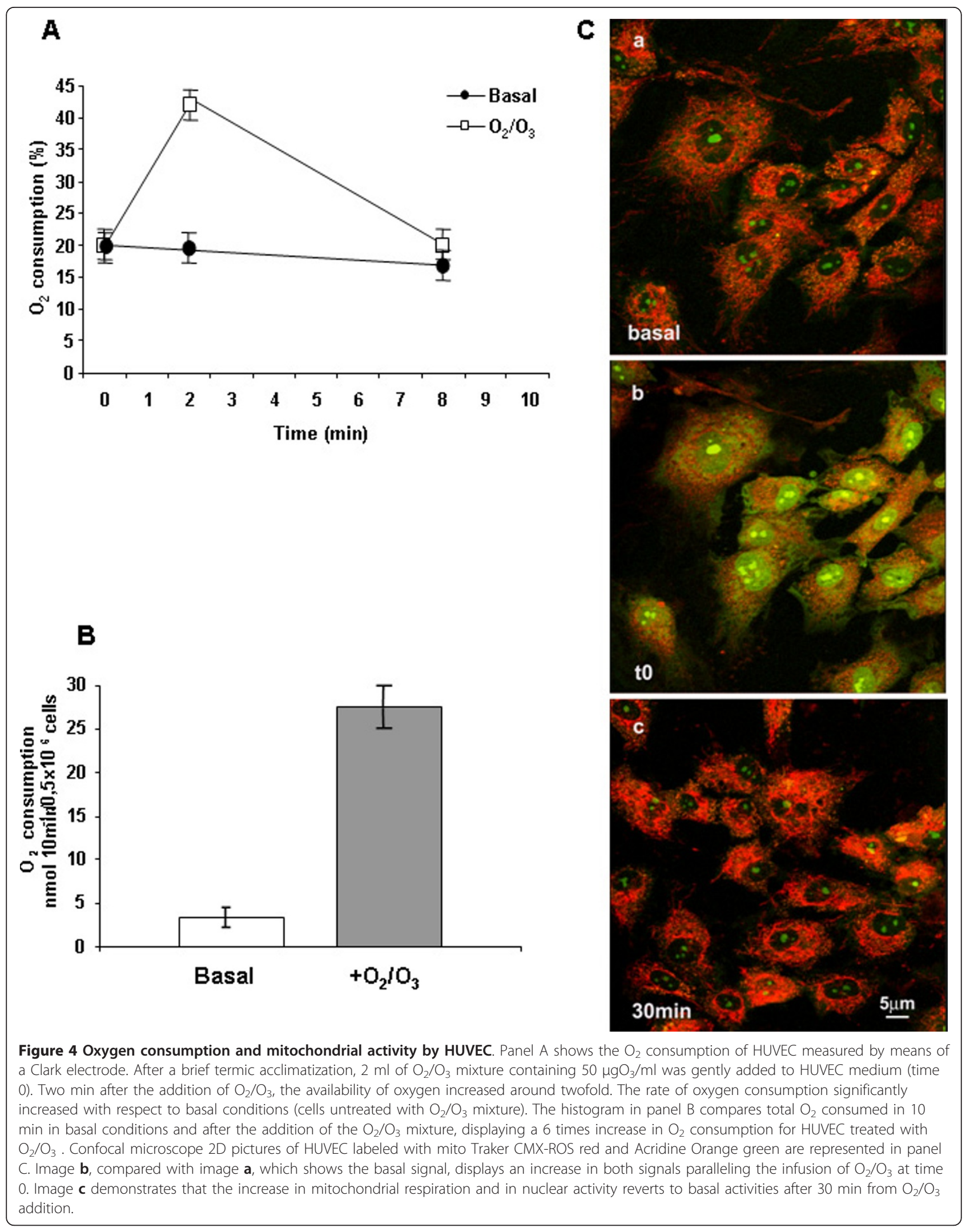


ATP
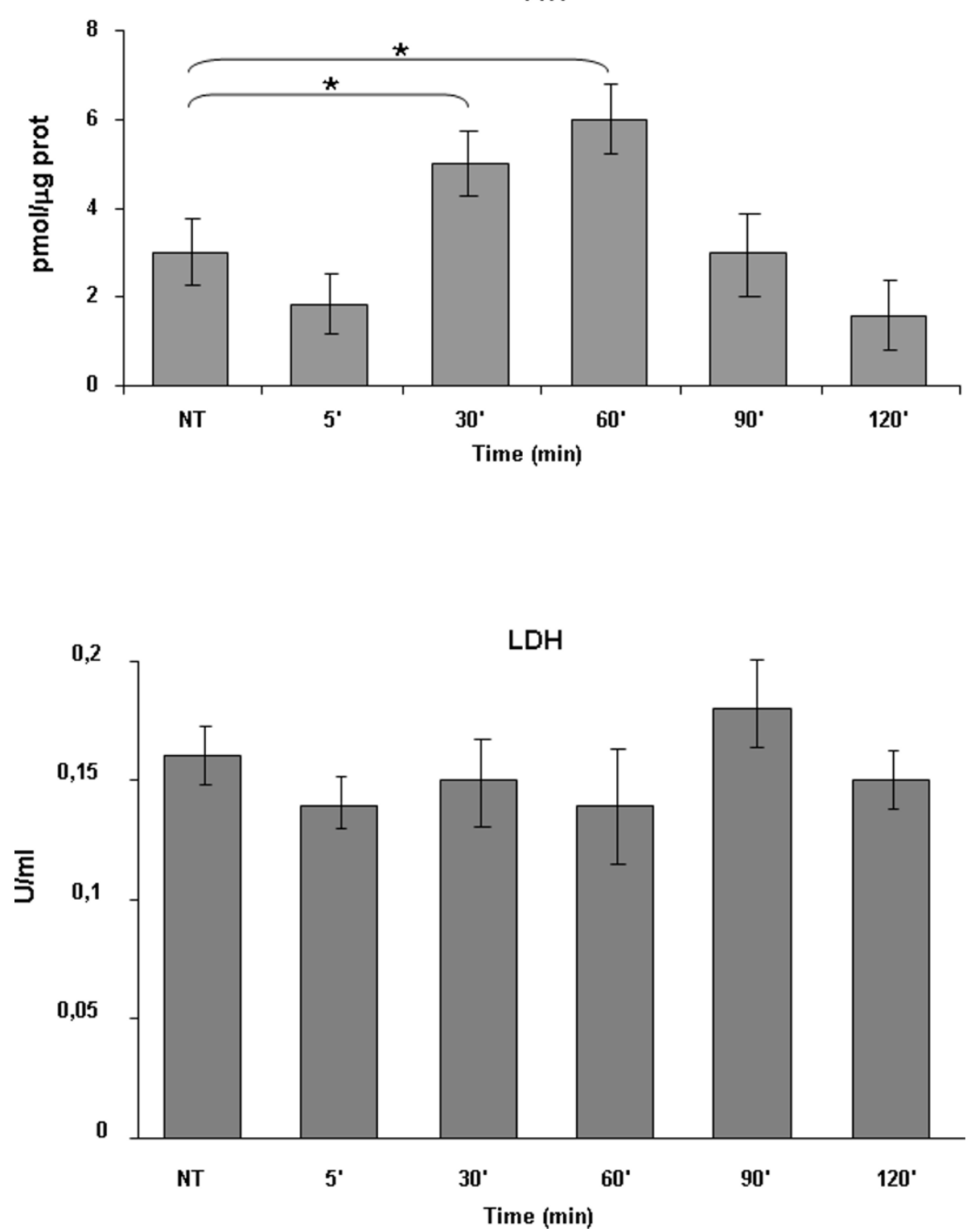

Figure 5 ATP and LDH levels in HUVEC at different times from exposure to $\mathrm{O}_{2} / \mathrm{O}_{3}$ mixture. The data represent the $\mathrm{m} \pm \mathrm{SEM}$ of 4 experiments. *P $<0.05$ vs NT (not treated), e.g. not exposed to $\mathrm{O}_{2} / \mathrm{O}_{3}$ mixture.

OA was effective in the protection against damage due to renal Isc/R, often provoked in patients by atherosclerotic renal artery stenosis.. Since the damage due to $R$ is very early [23], we decided to use a short time of reperfusion (e.g. $1 \mathrm{~h}$ ), also in consideration that some other previous works $[7,9]$ have already reported the usefulness of $\mathrm{O}_{2} / \mathrm{O}_{3}$ treatment at longer reperfusion times. Our results show that OA significantly improves kidney functional parameters compromised by Isc and Isc/R. In fact, increases of serum creatinine and blood urea nitrogen levels are significantly reduced following OA (Figure 1). Histology shows that OA significantly reduces medullary congestion and tubular dilation provoked by Isc and Isc/R, and only slightly reduces protein casts (Figure 2 and Table 2). However, the protection on the renal function induced by OA does not correlate with an increase in NO production. An activation of iNOS by OA treatment is shown the alteration of $\mathrm{NO} /$ NOS pool occurring after Isc injury may play a protective or a damaging role. The analysis of the $\beta \mathrm{NADPH}$ diaphorase shows that the $\mathrm{OA}$ increases the enzyme activity in the cortical tubules and in the glomeruli of the kidney, only after Isc, suggesting an increase in NO local production following the blood supply 
interruption. In rat kidneys, increased glomerular $\beta \mathrm{NADPH}$ diaphorase, e.g. local synthesis of NO, after renal Isc, seems to be a protective mechanism that counteracts vasoconstrictor and inflammatory phenomena occurring during the $\mathrm{R}$ period. However, as previously reported, since Isc/ $R$ injury can activate inflammatory reactions, Isc/R-induced renal NO level may be related to a increase of nuclear factor kappa Bdependent pro-inflammatory factors, which play a major role in the activation of iNOS during the inflammatory process [24]. Moreover, increased NO in reperfused kidney might be greatly enhanced by a simultaneous increase in superoxide radicals [25]. In our experimental model OA seems to be protective against Isc/R injury via $\mathrm{NO}$ generation.

Endothelial injury occurs rapidly after an ischemic insult [23] and relates to reduced mitochondrial activity [15]. Because Krebs cycle and mitochondrial mass are early victims of endothelial dysfunction [26], to better evidence the possible influence of $\mathrm{O}_{2} / \mathrm{O}_{3}$ treatment on the modulation of endothelial dysfunction, we have determined the mitochondrial functions of HUVEC through their capability to consume $\mathrm{O}_{2}$. Recently, it has been demonstrated that decrease in $\mathrm{O}_{2}$ consumption by pulmonary artery endothelial cells from patients affected by idiopathic pulmonary arterial hypertension was related to a decreased mitochondrial activity for these cells [27]. Previously, the effect of ozonated serum on HUVEC has been investigated and a dose-dependent increase of hydrogen peroxide as the main mediator of ozone action (possibly through an increase of NO production) was shown [28]. In our experiments, HUVEC display a low rate of oxygen consumption in basal conditions. The addition of $\mathrm{O}_{2} / \mathrm{O}_{3}$ mixture significantly increases the oxygen availability and the rate of oxygen consumption (Figure 4A and 4B). In parallel, confocal microscopy evidences a marked increase of mitochondrial activity, as revealed by mito Traker (Figure 4C, red signal). We can argue that, whereas in basal conditions ATP is generated nearly equivalently by glycolysis and cellular respiration [27], $\mathrm{O}_{2} / \mathrm{O}_{3}$ treatment stimulates the mitochondrial energetic metabolism of HUVEC, as shown, within 30-60 min, by a significant increase in ATP levels. Because in the same time intervals LDH levels of HUVEC do not significantly vary, the increase of ATP is attributable to the increase of mitochondrial instead of glycolytic pathway. Indeed, the $\mathrm{O}_{2} / \mathrm{O}_{3}$ mixture could restore the energy production also in vivo, when the reduction of available $\mathrm{O}_{2}$ due to Isc impairs endothelial cell respiration, favouring only their glycolytic activity. ATP reverted to basal levels after $90 \mathrm{~min}$ exposure to $\mathrm{O}_{2} / \mathrm{O}_{3}$ mixture, indicating that the shift from glycolytic to mitochondrial pathway, induced by $\mathrm{O}_{2} / \mathrm{O}_{3}$ treatment, was transient and fully reversible.
Injured endothelial cells reduce mitochondrial functions [26]. Since $\mathrm{O}_{2} / \mathrm{O}_{3}$ treatment improves endothelial respiration, with a more elevated production of ATP, we can argue that $\mathrm{O}_{2} / \mathrm{O}_{3}$ could preserve endothelial cells from dysfunction. Collectively, our results are the first evidence on OA mechanism of action on cell metabolism.

\section{Conclusions}

The preservation of endothelial metabolic activity could in vivo limit endothelial dysfunction provoked by the Isc or Isc/R processes. Because AO but not autohemotherapy with $\mathrm{O}_{2}$ alone is able to reduce endothelial dysfunction caused by Isc/R, we hypothesize that $\mathrm{O}_{3}$, which is endowed with anti-inflammatory properties, could limit the endotehlial activation provoked by some pro-inflammatory cytokines released during Isc/R processes. Finally, since Isc and Isc/R damages represent complications in atherosclerotic processes, we propose OA as a promising intervention in atherosclerotic patients.

\section{Author details}

${ }^{1}$ Clinical Cardiovascular Biology Laboratory, San Raffaele Scientific Institute, Milano, Italy. ${ }^{2}$ Dipartimento di Morfologia Umana e Scienze Biomediche Città Studi, Università degli Studi di Milano, Milan, Italy. ${ }^{3}$ Department of Oncology, IRCCS H San Raffaele, Milan, Italy. ${ }^{4}$ Laboratory of Lymphoid Malignancies, San Raffaele Scientific Institute, Milan, Italy.

\section{Authors' contributions}

CF performed histological, immunohisochemical analyses and confocal microscopy on HUVEC. AF performed animal studies, $\mathrm{O} 2$ consumption and collected samples. DB performed isolation and culture of HUVEC, measure ATP LDH and protein levels in HUVEC. CS performed Nitrite/Nitrate determination. EF coordinated the in vitro studies. MEF coordinated the in vivo studies and wrote and edited the manuscript. All authors read and approved the final manuscript.

\section{Competing interests}

The authors declare that they have no competing interests.

Received: 21 December 2010 Accepted: 14 November 2011

Published: 14 November 2011

\section{References}

1. Bocci V: Ozone as Janus: this controversial gas can be either toxic or medically useful. Mediators Inflamm 2004, 13(1):3-11.

2. Di Paolo N, Bocci V, Gaggiotti E: Ozone therapy. Int J Artif Organs 2004, 27(3):168-175.

3. Giunta R, Coppola A, Luongo C, Sammartino A, Guastafierro S, Grassia A, Giunta L, Mascolo L, Tirelli A, Coppola L: Ozonized autohemotransfusion improves hemorheological parameters and oxygen delivery to tissues in patients with peripheral occlusive arterial disease. Ann Hematol 2001, 80(12):745-748.

4. Coulson MT, Jablonski P, Howden BO, Thomson NM, Stein AN: Beyond operational tolerance: effect of ischemic injury on development of chronic damage in renal grafts. Transplantation 2005, 80(3):353-361.

5. Hancock WH, Whitley WD, Tullius SG, Heemann UW, Wasowska B, Baldwin WM, Tilney NL: Cytokines, adhesion molecules, and the pathogenesis of chronic rejection of rat renal allografts. Transplantation 1993, 56(3):643-650.

6. Ajamieh HH, Berlanga J, Merino N, Sanchez GM, Carmona AM, Cepero SM, Giuliani A, Re L, Leon OS: Role of protein synthesis in the protection 
conferred by ozone-oxidative-preconditioning in hepatic ischaemia/ reperfusion. Transpl Int 2005, 18(5):604-612.

7. Pagliaro P, Chiribiri A, Mancardi D, Rastaldo R, Gattullo D, Losano G: Coronary endothelial dysfunction after ischemia and reperfusion and its prevention by ischemic preconditioning. Ital Heart J 2003, 4(6):383-394.

8. Chen H, Xing B, Liu X, Zhan B, Zhou J, Zhu H, Chen Z: Similarities between ozone oxidative preconditioning and ischemic preconditioning in renal ischemia/reperfusion injury. Arch Med Res 2008, 39(2):169-178.

9. Chen H, Xing B, Liu X, Zhan B, Zhou J, Zhu H, Chen Z: Ozone oxidative preconditioning protects the rat kidney from reperfusion injury: the role of nitric oxide. J Surg Res 2008, 149(2):287-295.

10. Di Paolo N, Gaggiotti E, Galli F: Extracorporeal blood oxygenation and ozonation: clinical and biological implications of ozone therapy. Redox Rep 2005, 10(3):121-130.

11. Legrand M, Mik EG, Johannes T, Payen D, Ince C: Renal hypoxia and dysoxia after reperfusion of the ischemic kidney. Mol Med 2008, 14(78):502-516.

12. Duranski MR, Greer JJ, Dejam A, Jaganmohan S, Hogg N, Langston W, Patel RP, Yet SF, Wang X, Kevil CG, et al: Cytoprotective effects of nitrite during in vivo ischemia-reperfusion of the heart and liver. J Clin Invest 2005, 115(5):1232-1240

13. Foglieni C, Fulgenzi A, Ticozzi P, Pellegatta F, Sciorati C, Belloni D, Ferrero E, Ferrero ME: Protective effect of EDTA preadministration on renal ischemia. BMC Nephrol 2006, 7:5.

14. Molina A, Ubeda M, Escribese MM, Garcia-Bermejo L, Sancho D, Perez de Lema G, Liano F, Cabanas C, Sanchez-Madrid F, Mampaso F: Renal ischemia/reperfusion injury: functional tissue preservation by antiactivated \{beta\}1 integrin therapy. J Am Soc Nephrol 2005, 16(2):374-382.

15. Racusen LC: Alterations in tubular epithelial cell adhesion and mechanisms of acute renal failure. Lab Invest 1992, 67(2):158-165.

16. Green LC, Wagner DA, Glogowski J, Skipper PL, Wishnok JS, Tannenbaum SR: Analysis of nitrate, nitrite, and [15N]nitrate in biological fluids. Anal Biochem 1982, 126(1):131-138.

17. Aiello S, Noris M, Todeschini M, Zappella S, Foglieni C, Benigni A, Corna D, Zoja C, Cavallotti D, Remuzzi G: Renal and systemic nitric oxide synthesis in rats with renal mass reduction. Kidney Int 1997, 52(1):171-181.

18. Ferrero E, Ferrero ME, Pardi R, Zocchi MR: The platelet endothelial cell adhesion molecule-1 (PECAM1) contributes to endothelial barrier function. FEBS Lett 1995, 374(3):323-326.

19. CRC Handbook of Chemistry and Physics. Cleveland: Chemical Rubber Pub. Co; 892008

20. Foglieni C, Meoni C, Davalli AM: Fluorescent dyes for cell viability: an application on prefixed conditions. Histochem Cell Biol 2001, 115(3):223-229.

21. Ferrero $E_{1}$ Fulgenzi $A$, Belloni $D$, Foglieni $C$, Ferrero ME: Cellfood improves respiratory metabolism of endothelial cells and inhibits hypoxia-induced reactive oxygen species (ROS) generation. J Physiol Pharmacol 2011, 62(3):287-293.

22. Duda M, Czarnowska E, Kurzelewski M, Konior A, Beresewicz A: Ischemic preconditioning prevents endothelial dysfunction, P-selectin expression, and neutrophil adhesion by preventing endothelin and O2- generation in the post-ischemic guinea-pig heart. J Physiol Pharmacol 2006, 57(4):553-569.

23. Basile DP: The endothelial cell in ischemic acute kidney injury: implications for acute and chronic function. Kidney Int 2007, 72(2):151-156.

24. Altunoluk B, Soylemez H, Oguz F, Turkmen E, Fadillioglu E: An Angiotensinconverting enzyme inhibitor, zofenopril, prevents renal ischemia/ reperfusion injury in rats. Ann Clin Lab Sci 2006, 36(3):326-332.

25. Karaman A, Turkmen E, Gursul C, Tas E, Fadillioglu E: Prevention of renal ischemia/reperfusion-induced injury in rats by leflunomide. Int J Urol 2006, 13(11):1434-1441

26. Addabbo F, Ratliff B, Park HC, Kuo MC, Ungvari Z, Csiszar A, Krasnikov B, Sodhi K, Zhang F, Nasjletti A, et al: The Krebs cycle and mitochondrial mass are early victims of endothelial dysfunction: proteomic approach. Am J Pathol 2009, 174(1):34-43.

27. Xu W, Koeck T, Lara AR, Neumann D, DiFilippo FP, Koo M, Janocha AJ, Masri FA, Arroliga AC, Jennings $C$, et al: Alterations of cellular bioenergetics in pulmonary artery endothelial cells. Proc Natl Acad SCi USA 2007, 104(4):1342-1347.
28. Valacchi G, Bocci V: Studies on the biological effects of ozone: 11 . Release of factors from human endothelial cells. Mediators Inflamm 2000, 9(6):271-276

\section{Pre-publication history}

The pre-publication history for this paper can be accessed here: http://www.biomedcentral.com/1471-2369/12/61/prepub

doi:10.1186/1471-2369-12-61

Cite this article as: Foglieni et al:: Ozonated autohemotherapy: protection of kidneys from ischemia in rats subjected to unilateral nephrectomy. BMC Nephrology 2011 12:61.

\section{Submit your next manuscript to BioMed Central and take full advantage of:}

- Convenient online submission

- Thorough peer review

- No space constraints or color figure charges

- Immediate publication on acceptance

- Inclusion in PubMed, CAS, Scopus and Google Scholar

- Research which is freely available for redistribution

Submit your manuscript at www.biomedcentral.com/submit
Ciomed Central 